\title{
Sistem Pendukung Keputusan Pemilihan Transportasi Online Dengan Metode Simple Additive Weighting
}

\author{
Devara Putra Aryasa ${ }^{1}$, Magdalena A. Ineke Pakereng ${ }^{2}$ \\ ${ }^{1,2}$ Fakultas Teknologi Informasi, Universitas Kristen Satya Wacana \\ Jl. Diponegoro 52-60, Salatiga 50711, Indonesia \\ e-mail: ${ }^{1672016059 @ s t u d e n t . u k s w . e d u, ~}{ }^{2}$ ineke.pakereng@uksw.edu
}

Informasi Artikel Diterima: 19-02-2021 Direvisi: 12-04-2021 Disetujui: 06-05-2021

\begin{abstract}
Abstrak
Teknologi semakin berkembang seiring dengan perkembangan jaman. Perkembangan tersebut memiliki dampak terhadap hampir seluruh lapangan pekerjaan, salah satunya adalah bisnis di bidang transportasi. Bisnis transportasi yang begitu cepat pertumbuhannya yaitu transportasi online seperti Gojek dan Grab. Dengan penjelasan tersebut, peneliti tertarik untuk meneliti dengan tujuan untuk mengetahui apakah masyarakat Citayam lebih sering menggunakan Gojek atau Grab. Peneliti menggunakan metode SAW (Simple Additive Weighting) untuk mengetahui hasil dari kasus yang diteliti. Pengumpulan data dilakukan dengan menyebarkan kuesioner terhadap 50 responden masyarakat Citayam. Penelitian ini dilakukan untuk mengetahui kualitas pelayanan, harga dan kepuasan konsumen terhadap Grab dan Gojek, serta membandingkan tingkat minat pelanggan daerah Citayam dalam memilih Gojek dan Grab. Hasil menunjukkan bahwa masyarakat di daerah Citayam lebih memilih menggunakan layanan Grab daripada Gojek, dalam hal ini Gojek harus lebih meningkatkan kualitas pelayanan serta promo. Grab memiliki nilai preferensi 0.95 dan Gojek memiliki nilai preferensi 0.94 .
\end{abstract}

Kata Kunci: Metode SAW, Transportasi, Teknologi

\begin{abstract}
Technology is increasingly developing along with the times. This development has an impact on almost all jobs, one of which is the business in the transportation sector. The transportation business that is growing so fast is online transportation such as Gojek and Grab. With this explanation, researchers are interested in researching with the aim of finding out whether Citayam people use Gojek or Grab more often. Researchers used the SAW (Simple Additive Weighting) method to determine the results of the cases studied. Data collection was carried out by distributing questionnaires to 50 Citayam community respondents. This research was conducted to determine service quality, price and consumer satisfaction with Grab and Gojek, as well as to compare the level of interest of Citayam area customers in choosing Gojek and Grab. The results show that people in the Citayam area prefer to use Grab services rather than Gojek, in this case Gojek must further improve the quality of services and promos. Grab has a preference value of 0.95 and Gojek has a preference value of 0.94
\end{abstract}

Keywords: SAW Methods, Transportation, Technology

\section{Pendahuluan}

Menurut Kementerian Komunikasi Dan Informatika Republik Indonesia, 2015 bahwa Indonesia merupakan raksasa teknologi digital asia yang sedang tertidur. Menurut data dari Kementerian Komuniaksi dan Informatika Republik Indonesia, 2014. Indonesia merupakan negara dengan penggunaan internet terbesar ke-8 di dunia sebesar 82 juta jiwa. Perkembangan penggunaan internet ini meningkatan kreatifitas anak bangsa mulai dari pembuatan start up digital, saat ini banyak sekali perusahaan-perusahaan besar yang memulai karirnya dari mulai start up seperti Gojek, Grab, Tokopedia, Bukalapak, LakuLaku, Traveloka dan sebagaimananya.

Dalam start up di bidang transportasi online, peran gojek dan grab menjadi yang paling sering digunakan oleh masyarakat, menurut data(sumber). Maka dari itu peran gojek maupun grab sebagai transportasi online menjadi sangat penting bagi masyarakat dalam menajalankan aktifitas. 
Gojek dan Grab adalah jenis transportasi online yang identik dengan warna hijau pada logo perusahaannya, fitur kayanan yang hamper sama serta tariff harga yang bersaing. Penelitian ini dilakukan untuk mengetahui dan membandingkan tingkat minat customer daerah citayam dalam memilih gojek dan grab sebagai opsi transportasi online dalam menjalankan aktifitasnya. Serta bagi pihak perusahaan dapat dijadikan sebagai acuan dalam meningkatkan kualitas pelayanan(Dian, 2019). Berdasarkan latar belakang tersebut, makan dilakukan penelitian yang berjudul Sistem Pendukung Keputusan Pemilihan Transportasi Online Dengan Metode SAW (Simple Additive Weighting) (Studi Kasus : Citayam.

Penelitian ini bertujuan untuk mencari rekomendasi transportasi online yang paling banyak diminati, dilihat dari beberapa kriteria penelian. Hal ini bisa menjadi evaluasi untuk para pengembang transportasi online agar memperbaiki dari 12 kriteria penelitian yang kurang. Melakukan observasi dan wawancara pada tempat kejadian merupakan penelitian lapangan, sedangkan perancangan dan pembuatan program dari data yang didapatkan merupakan penelitian laboratorium. Metode yang digunakan dalam penelitian ini adalah dengan menggunakan kuesioner dengan jumlah 50 sebagai sampel data(Thoybah, Akhmad Suharto, n.d.).

Pada penelitian sebelumnya, penerapan metode SAW (Simple Additive Weighting) digunakan untuk Sistem Pendukung Keputusan Penentuan Penerimaan Beasiswa Bantuan Siswa Miskin (BSM). Pada SMA Negeri 1 Subuh KAB, Batang. Sistem SAW digunakan untuk Menentukan Penerima Beasiswa, penelitian ini membahas pemanfaatan metode SAW untuk proses seleksi BSM di tingkat sekolah serta meningkatkan akurasi penerimaan secara tepat sasaran (Rinaldhi, 2011).

Penelitian lain juga dilakukan dengan menerapkan metode SAW (Simple Additive Weighting) dalam Sistem Pendukung Keputusan Penentuan Karyawan Terbaik pada PT ISS Indonesia Cabang Medan. Penelitian ini digunakan untuk pengambilan keputusan karyawan terbaik dan juga sebagai prosedur penelitian dalam mengambil keputusan pemilihan karyawan terbaik agar pemilihan karyawan terbaik agar pemilihan karyawan terbaik dapat dilakukan dengan proses terstruktur (Manahan, 2016).

Dalam penelitian lainnya, penerapan metode SAW (Simple Additive Weighting) digunakan sebagai Analisis dan Perencanaan Sistem Pendukung Keputusan Pemberian
Bonus Tahunan Karyawan yang telah memberikan loyalitas maupun dedikasi yang tinggi bagi perusahaan. Sistem yang dikembangkan guna menunjang keputusan perusahaan meliputi data karyawan, dan kriteria, data perhitungan bobot kriteria, data penilaian kinerja karyawan karyawan, hasil perhitungan penentuan karyawan yang mendapatkan bonus tahunan, dan laporan karyawan penerimaan bonus tahunan (Ningrum et al., 2016).

Berdasarkan penelitian diatas, untuk penelitian ini metode SAW ((Simple Additive Weighting) diterapkan dengan tujuan agar dapat digunakan untuk mencari perbandingan dua variable atau lebih dengan berdasarkan kriteria pembanding yang dilakukan secara studi kasus di daerah Citayam, Kota Depok.

Sistem pendukung keputusan merupakan sistem interaktif (berbasis computer) yang membantu manusia dalam hal komunikasi, data, dokumen, pengetahuan dan model untuk memecahkan masalah dalam membuat keputusan. Sistem pendukung keputusan adalah tambahan atau penunjang sistem, dalam artian harus bisa memfasilitasi proses pengambilan keputusan.

Tahapan dalam metode SAW adalah dengan mencari nilai tertinggi dari variabel yang akan dipilih. Metode SAW adalah metode yang dilakukan dengan cara mencari hasil dari penjumlahan berbobot dari rating kinerja pada setiap atribut, hasil dari penjumlahan berbobot itu akan digunakan sebagai pedoman dalam pengambilan keputusan. Kriteria yang terdapat pada metode SAW merupakan kriteria yang dibutuhkan dan ditentukan sendiri oleh setiap orang atau perusahaan (Agetia et al., 2020).

Tahapan dalam metode SAW sebagai berikut :

1) Menentukan nilai bobot preferensi atau tingkat kepentingan $(B)$ pada setiap kriteria yang telah didapatkan. $i$ pada $B$ menggambarkan jumlah bobot preferensi dalam sebuah kasus.

$B=\left[\begin{array}{lllll}B 1 & B 2 & B 3 & \ldots & B i\end{array}\right]$.

2) Menghitung normalisasi pada matriks kriteria terhadap nilai rating kinerja ternomalisasi $\left(r_{i j}\right) . x_{i j}$ merupakan nilai atribut yang dimiliki setiap kriteria.

$$
r_{i j}=\left\{\begin{array}{l}
\frac{x_{i j}}{M_{i}\left(x_{i j}\right)} \\
M_{i}\left(x_{i j}\right) \\
x_{i j}
\end{array}\right.
$$

Jika $\mathrm{J}$ adalah atribut benefit....(2)

Jika $\mathrm{J}$ adalah atribut cost...(3) 
3) Merubah nilai $r_{i j}$ menjadi matriks ternomalisasi

$$
N=\left[\begin{array}{ccc}
r_{11} & \cdots & r_{1 j} \\
\vdots & \vdots & \vdots \\
r_{i 1} & \cdots & r_{i j}
\end{array} \mid\right.
$$

4) Perhitungan perangkingan dilakukan dengan mengkalikan matrik ternomalisasikan dengan nilai bobot preferensi $(B)$.

5) Untuk mendapatkan nilai preferensi untuk setiap alternatif $\left(V_{i}\right)$ dilakukan dengan menambahkan hasil kali dari matrik ternomalisasi $(M)$ dengan nilai bobot preferensi $(B)$.

$$
V_{i}=\sum_{j=1}^{n} B_{j} r_{i j}
$$

\section{Metode Penelitian}

Dalam penelitian ini terbagi menjadi tiga tahap, yaitu : satu tahap indentifikasi masalah, dua pengumpulan data, tiga perancangan aplikasi, empat analisa.

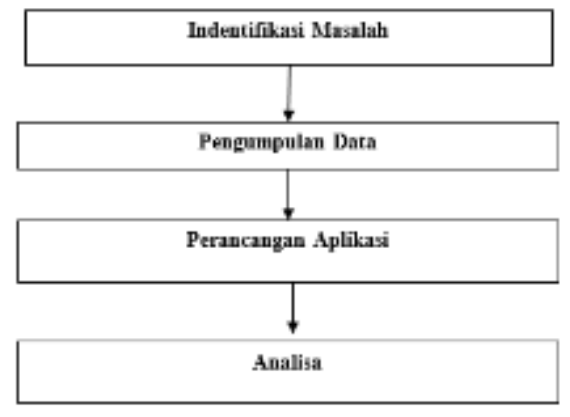

Gambar 1. Tahapan penelitian

Tahap penelitian dapat dilihat pada gambar 1 dan dijelaskan sebagai berikut :

Langkah pertama yaitu indentifikasi masalah yang terjadi pada kategori pelayanan transportasi online grab dan gojek terkait dengan banyak nya peminat secara kualitas dari transportasi tersebut. Langkah kedua pengumpulan data yaitu dengan melakukan penyebaran kuesioner secara umum di daerah citayam, sehingga didapatkan berupa kriteriakriteria yang di butuhkan dalam proses perhitungan bagi yang menggunakan aplikasi gojek maupun grab. Lalu ketiga perancangan aplikasi dengan berbasis web menggunakan PHP sebagai bahasa pemograman dan MySQL sebagai database. Tahap selanjutnya analisa yaitu menganalisis data kuesioner yang telah disebar dan dimasukan kedalam aplikasi yang telah dibuat.

\section{Hasil dan Pembahasan}

Pada penelitian ini menggunakan 50 sampel data sebagai indikator untuk menentukan banyaknya peminat masyarakat terhadap transportasi grab dan gojek berdasarkan kriteria berikut ini :

Tabel 1. Bobot prefensi berdasarkan kriteria

\begin{tabular}{lc}
\hline \multicolumn{1}{c}{ Kriteria } & Bobot \\
\hline $\begin{array}{l}\text { Kemudahaan Menggunakan } \\
\text { Fitur dalam aplikasi (C1) }\end{array}$ & 9 \\
$\begin{array}{l}\text { Kelengkapan Menggunakan } \\
\text { Fitur dalam aplikasi (C2) }\end{array}$ & 9 \\
$\begin{array}{l}\text { Kepuasan terhadap pelayanan } \\
\text { yang diberikan driver (C3) }\end{array}$ & 9 \\
$\begin{array}{l}\text { Harga yang ditawarkan } \\
\text { terjangkau (C4) }\end{array}$ & 9 \\
$\begin{array}{l}\text { Menggunakan aplikasi tersebut } \\
\text { tidak membutuhkan waktu lama }\end{array}$ & 9 \\
$\begin{array}{l}\text { untuk mendapatkan pengemudi } \\
\text { (C5) }\end{array}$ & \\
$\begin{array}{l}\text { Kemudahan fitur kirim barang } \\
\text { (C6) }\end{array}$ & 9 \\
$\begin{array}{l}\text { Kemudahan fitur pesan } \\
\text { makanan (C7) }\end{array}$ & 8 \\
$\begin{array}{l}\text { Banyak promo yang di dapatkan } \\
\text { (C8) }\end{array}$ & 8 \\
$\begin{array}{l}\text { Driver menjemput tepat waktu } \\
\text { sesuai prediksi di aplikasi (C9) }\end{array}$ & 8 \\
$\begin{array}{l}\text { Pengiriman makanan tepat } \\
\text { waktu (C10) }\end{array}$ & 8 \\
$\begin{array}{l}\text { Driver ramah terhadap } \\
\text { pelanggan (C11) }\end{array}$ & 7 \\
$\begin{array}{l}\text { Pengiriman barang tepat waktu } \\
\text { (C12) }\end{array}$ & 7 \\
\hline
\end{tabular}

Dari indikator tersebut, dituangkan ke dalam kuesioner yang ditunjukan bagi masyarakat daerah Citayam yang menggunakan aplikasi transportasi online gojek maupun grab.

Tabel 2. Rating kecocokan setiap kriteria

\begin{tabular}{clll}
\hline Kriteria & Gojek & Grab & Bobot \\
\hline (C1) & 217 & 217 & $9 \%$ \\
$(\mathrm{C} 2)$ & 227 & 219 & $9 \%$ \\
$(\mathrm{C} 3)$ & 215 & 207 & $9 \%$ \\
$(\mathrm{C} 4)$ & 202 & 206 & $9 \%$ \\
$(\mathrm{C} 5)$ & 206 & 201 & $9 \%$ \\
$(\mathrm{C} 6)$ & 205 & 210 & $9 \%$ \\
$(\mathrm{C})$ & 219 & 210 & $8 \%$ \\
$(\mathrm{C})$ & 183 & 212 & $8 \%$ \\
$(\mathrm{C})$ & 201 & 201 & $8 \%$ \\
$(\mathrm{C} 10)$ & 211 & 214 & $8 \%$ \\
$(\mathrm{C} 11)$ & 217 & 211 & $7 \%$ \\
$(\mathrm{C} 12)$ & 216 & 217 & $7 \%$ \\
\hline
\end{tabular}


Pada tabel 2 berisi tentang penilaian kecocokan setiap kriteria, penilaian tersebut didasarkan dengan bobo kemudian hasil dijadikan satuan persen dan diubah menjadi matrik.

$$
N=\left[\begin{array}{ll}
217 & 217 \\
227 & 219 \\
215 & 207 \\
202 & 206 \\
206 & 201 \\
205 & 210 \\
219 & 210 \\
183 & 212 \\
201 & 201 \\
211 & 214 \\
217 & 211 \\
216 & 217
\end{array}\right]
$$

Dari data pada tabel 2 dirubah menjadi matrik, selanjutnya matrik $N$ diubah menjadi matrik normalisasi dan berikut matrik $N$ setelah di normalisasi.

$$
N=\left[\begin{array}{cc}
1 & 1 \\
1 & 0.96 \\
1 & 0.96 \\
0.98 & 1 \\
1 & 0.97 \\
0.97 & 1 \\
1 & 0.95 \\
0.86 & 1 \\
1 & 1 \\
0.98 & 1 \\
1 & 0.97 \\
0.99 & 1
\end{array}\right]
$$

Setelah dirubah menjadi matrik normalisasi, proses selanjutnya untuk mendapatkan nilai prefensi dilakukan perhitungan mengenai bobot yang digunakan untuk mendapatkan banyaknya peminat dari transportasi gojek dan grab, yaitu : $B=$ $[9,9,9,9,9,9,8,8,8,8,7,7]$.

Tabel 3. Normalisasi Gojek dan Grab.

\begin{tabular}{cll}
\hline Kriteria & \multicolumn{1}{c}{ Gojek } & \multicolumn{1}{c}{ Grab } \\
\hline (C1) & $217 / 217=1$ & $217 / 217=1$ \\
(C2) & $227 / 227=1$ & $219 / 227=0.96$ \\
(C3) & $215 / 211=1$ & $207 / 215=0.96$ \\
(C4) & $202 / 206=0.98$ & $206 / 206=1$ \\
(C5) & $206 / 206=1$ & $201 / 206=0.97$ \\
(C6) & $205 / 210=0.97$ & $210 / 210=1$ \\
(C7) & $219 / 219=1$ & $210 / 219=0.95$ \\
(C8) & $183 / 212=0.86$ & $212 / 212=1$ \\
(C9) & $201 / 201=1$ & $201 / 201=1$ \\
(C10) & $211 / 214=0.98$ & $214 / 214=1$ \\
(C11) & $217 / 217=1$ & $211 / 217=0.97$ \\
(C12) & $216 / 217=0.99$ & $217 / 217=1$ \\
\hline
\end{tabular}

Pada tabel 3 mengenai cara perhitungan serta hasil normalisasi dari matrik.

Tabel 4. Hasil Normalisasi kali dengan bobot.

\begin{tabular}{cll}
\hline Kriteria & \multicolumn{1}{c}{ Gojek } & \multicolumn{1}{c}{ Grab } \\
\hline (C1) & $1^{*} 9 \%=0.09$ & $1^{*} 9 \%=0.09$ \\
(C2) & $1^{*} 9 \%=0.09$ & $0.96 * 9 \%=0.08$ \\
(C3) & $1^{*} 9 \%=0.09$ & $0.96 * 9 \%=0.08$ \\
(C4) & $0.98 * 9 \%=0.08$ & $1^{*} 9 \%=0.09$ \\
(C5) & $1^{*} 9 \%=0.09$ & $0.97^{*} 9 \%=0.08$ \\
(C6) & $0.97^{*} 9 \%=0.08$ & $1^{*} 9 \%=0.09$ \\
(C7) & $1^{*} 8 \%=0.08$ & $0.95 * 8 \%=0.07$ \\
(C8) & $0.86{ }^{*} 8 \%=0.06$ & $1^{*} 8 \%=0.08$ \\
(C9) & $1^{*} 8 \%=0.08$ & $1^{*} 8 \%=0.08$ \\
(C10) & $0.98^{*} 8 \%=0.07$ & $1^{*} 8 \%=0.08$ \\
(C11) & $1^{*} 7 \%=0.07$ & $0.97^{*} 7 \%=0.06$ \\
(C12) & $0.99^{*} 7 \%=0.06$ & $1^{*} 7 \%=0.7$ \\
\hline
\end{tabular}

Setelah data di normalisasikan maka hasil dari normalisasi dikalikan dengan bobot yang sudah diubah ke dalam bentuk satuan persen seperti pada tabel 4 .

Tabel 5. Hasil Akhir dari penjumlahan normalisasi kali dengan bobot

\begin{tabular}{ccc}
\hline Transportasi & Hasil & Keterangan \\
\hline Gojek & 0.94 & Peringkat 2 \\
Grab & 0.95 & Peringkat 1 \\
\hline
\end{tabular}

Hasil yang diperoleh dari perhitungan diatas, menghasilkan bahwa grab memiliki nilai preferensi yaitu 0.95 , sedangkan gojek memiliki nilai preferensi 0.94. dalam pembuatan aplikasi yang dilakukan yaitu membuat diagram yang diperlukan, berikut adalah diagram yang digunakan dalam perancangan sistem:

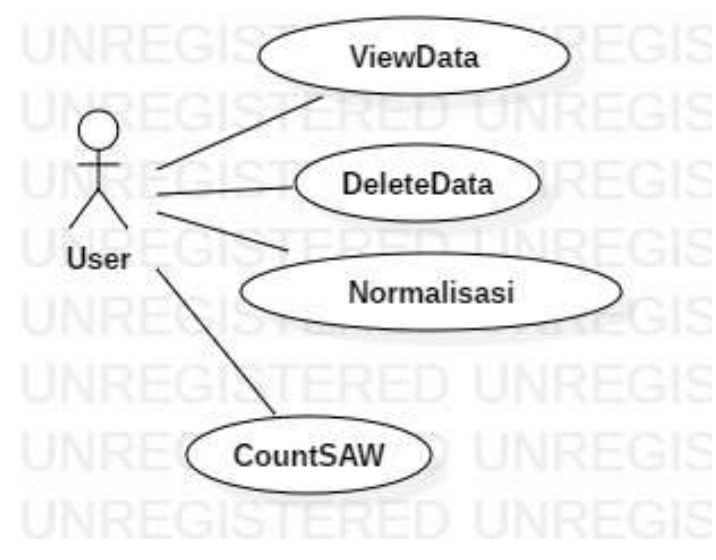

Gambar 2. Use case diagram

Dalam merancang suatu sistem dibutuhkan pembuatan simulasi agar sistem 
tersusun secara sistematis. Dalam program komputer terdapat bahasa permodelan yang dikhususkan untuk sistem dengan berbentuk grafik atau gambar yang disebut dengan Unified Modelling Language (UML) (Hendini, 2016).

UML memiliki beberapa bentuk grafik diantaranya Use Case Diagram dan Class Diagram. Use Case Diagram yang bertujuan untuk membuat gambaran tampilan luar dari sistem yang akan dibuat modelnya (Suendri, 2018). Dalam UML Didalam use case diagram pada gambar 1 memiliki 1 user dan user bisa melakukan view data yaitu user bisa melihat data grab dan data gojek, hapus data, view normalisasi. maksudnya user bisa melihat hasil dari data awal yang sudah dinormalisasikan dan user count SAW yaitu user bisa melihat hasil perhitungan dari SAW.

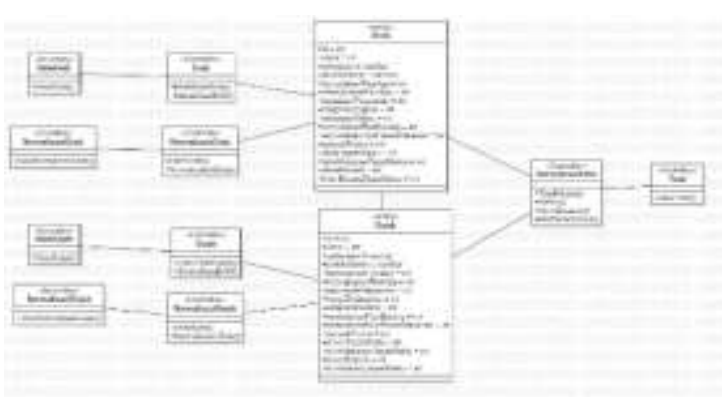

Gambar 3. Class diagram

Sedangkan Class Diagram merupakan gambaran mengenai struktur sistem sesuai dengan kelas-kelas penelitian yang dibuat (Putra \& Andriani, 201s9). Didalam class diagram pada gambar 3 memiliki lima boundary yaitu data gojek, data grab, normalisasi gojek, normalisasi grab secara keseluruhuan. Lima controller yaitu grab, gojek, normalisasi grab, normalisasi gojek. normalisasi total 2 entity yaitu : grab dan gojek.

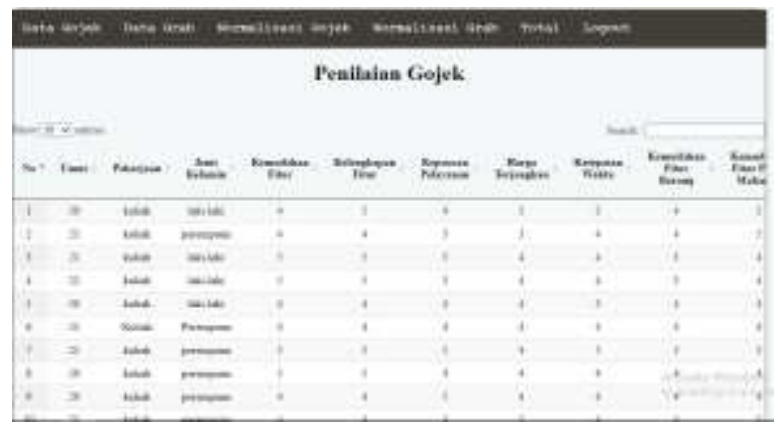

Gambar 4. Halaman Data Awal Gojek

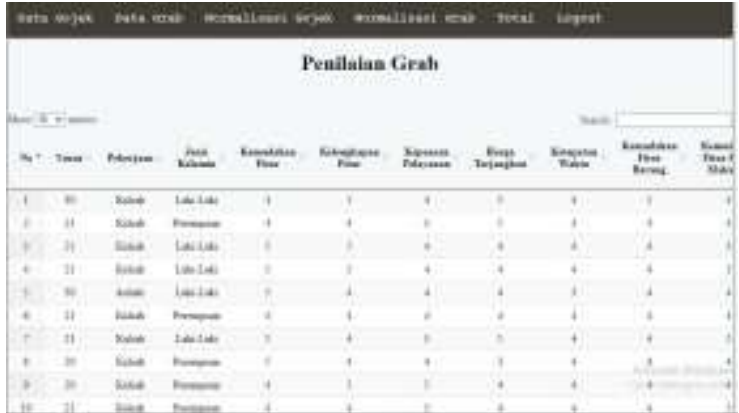

Gambar 5. Halaman Data Awal Grab

Pada gambar 4 dan gambar 5 merupakan tampilan berupa sampel data responden dari gojek dan grab yang telah dilakukan melalui penyebaran kuesioner di daerah citayam.

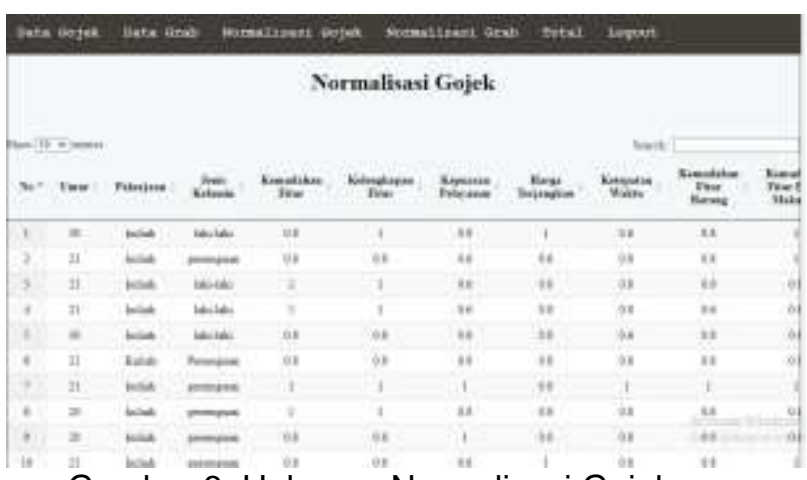

Gambar 6. Halaman Normalisasi Gojek

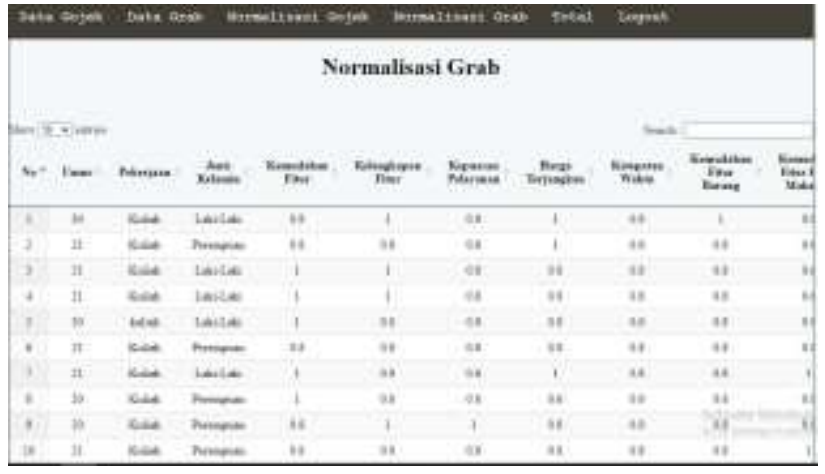

Gambar 7. Halaman Normalisasi Grab

Pada gambar 6 dan gambar 7 merupakan tampilan data respondes dari gojek dan grab yang sudah di normalisasikan. 

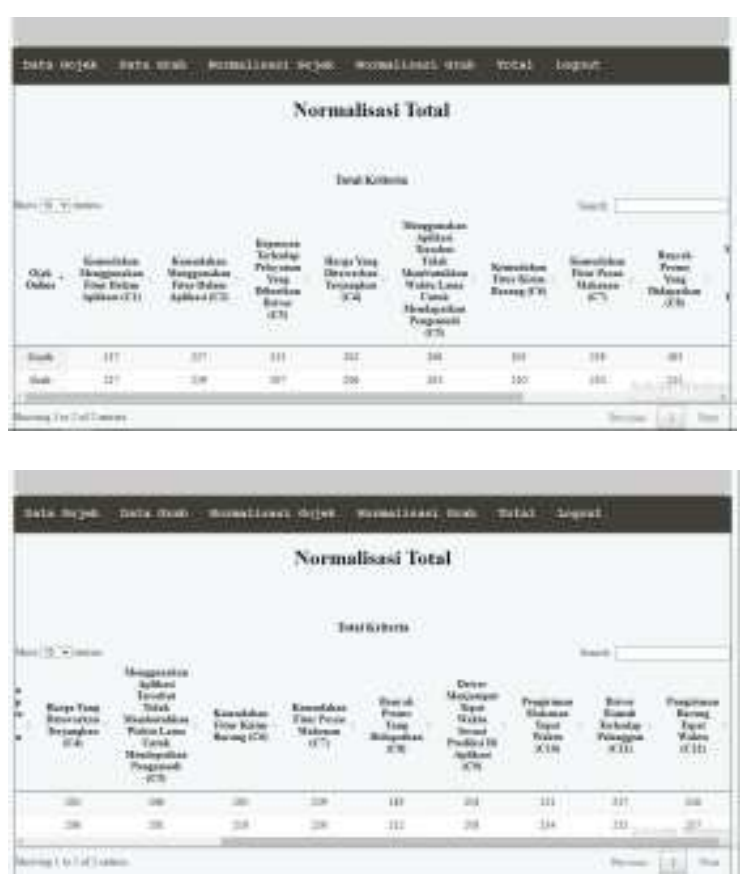

Gambar 8. Halaman Normalisasi Total Kriteria

Pada gambar 8 merupakan tampilan berupa jumlah dari hasil data responden gojek dan grab.

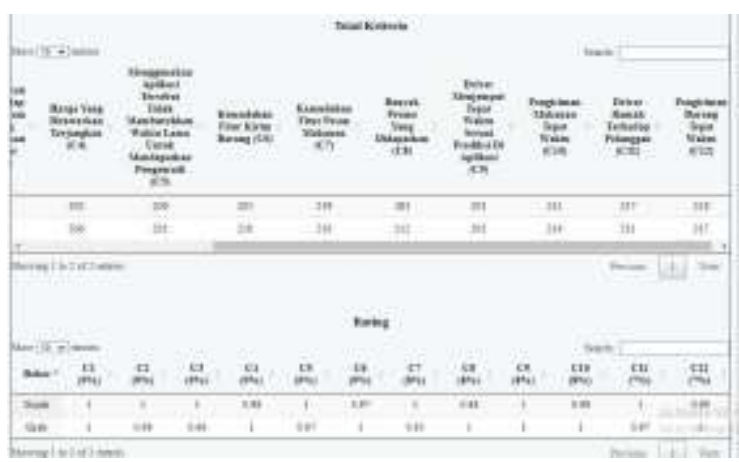

Gambar 9. Halaman Normalisasi Total Rating

Pada gambar 9 merupakan tampilan rating yaitu untuk menentukan tingkat banyak nya peminat antara transportasi grab dan gojek dan menentukan kualitas kriteria mana yang banyak diminati oleh masyarakan citayam.

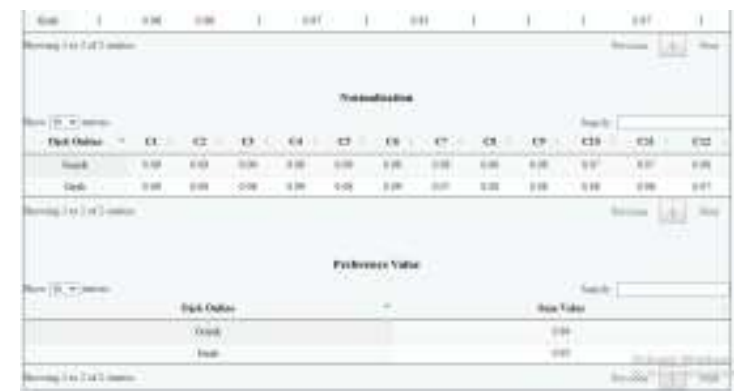

Gambar 10. Halaman Normalisasi Hasil
Pada gambar 10 yaitu tampilan preferensi dari 50 sampel data setiap kriteria transportasi online, yang menampilkan banyak nya peminat transportasi online serta menampilkan kriteria yang banyak diminati oleh masyarakat citayam.

\section{Kesimpulan}

Dari hasil penelitian ini dapat mengetahui bahwa dari 50 sampel data peminat yang paling diminati adalah pengguna grab daripada gojek, bahwa grab memiliki nilai preferensi 0.95 , sedangkan gojek memiliki nilai preferensi 0.94(Taslim, 2020)

Hasil penelitian ini juga dapat mengetahui kriteria-kriteria dari grab dan gojek yang harus ditingkatkan: untuk kriteria kemudahan menggunakan fitur dalam aplikasi(C2) yang lebih unggul yaitu transportasi gojek dengan nilai preferensi : 0.09, karena menurut data tersebut yang sudah diteliti bahwa aplikasi gojek lebih mudah digunakan bagi customer dibandingan aplikasi dari grab dengan nilai preferensi : 0.08 , dan untuk kriteria kepuasan pelayanan terhadap driver(C3) yang lebih unggul yaitu gojek dengan nilai preferensi : 0.09, karena menurut data tersebut yang sudah diteliti bahwa pelayanan driver gojek lebih memuaskan dari pada driver grab dengan nilai preferensi : 0.08 . Kemudian untuk kriteria harga terjangkau(C4) yang lebih unggul yaitu grab dengan nilai preferensi : 0.09, karena menurut data tersebut yang sudah diteliti bahwa harga biaya dari transportasi grab lebih terjangkau dari pada gojek dengan nilai preferensi : 0.08 , untuk kriteria ketepatan waktu driver(C5) yang lebih unggul yaitu gojek dengan nilai preferensi : 0.09 , karena menurut data yang sudah diteliti bahwa gojek cepat dalam menjemput customer dari pada grab dengan nilai preferensi : 0.08. Kemudian untuk kriteria kemudahan fitur aplikasi barang(C6) yang lebih unggul yaitu grab dengan nilai preferensi : 0.09, karena menurut data yang sudah diteliti bahwa fitur aplikasi barang yang dimiliki oleh grab lebih mudah digunakan dari pada fitur aplikasi barang di gojek dengan nilai preferensi : 0.08. Untuk kriteria kemudahan fitur pesan makanan(C7) yang lebih unggul yaitu gojek dengan nilai preferensi : 0.08, karena menurut data yang sudah diteliti bahwa fitur pesan makanan gojek lebih mudah digunakan dari pada fitur aplikasi pesan makanan di grab dengan nilai preferensi : 0.07 . Untuk kriteria banyak promo (C8) yang lebih unggul yaitu grab dengan nilai preferensi : 0.08 , karena menurut data yang sudah diteliti bahwa grab lebih banyak mengeluarkan promo daripada gojek dengan nilai preferensi : 0.06 . Kemudian 
untuk kriteria pengiriman makanan tepat waktu(C10) yang lebih unggul yaitu grab dengan nilai preferensi : 0.08 karena menurut data yang sudah diteliti bahwa grab lebih tepat waktu dari pada gojek dengan nilai preferensi : 0.07 , Kriteria driver ramah terhadap customer (C11) yang lebih unggul yaitu gojek dengan nilai preferensi : 0.07 , karena menurut data yang sudah diteliti bawah driver gojek itu lebih ramah daripada grab dengan nilai preferensi : 0.06 . Kemudian untuk kriteria pengiriman barang tepat waktu (C12) yang lebih unggul yaitu grab dengan nilai preferensi : 0.07 , karena menurut data yang sudah di teliti bahwa grab untuk pengiriman barang driver selalu tepat waktu daripada gojek dengan nilai preferensi : 0.06(Saipurrohman, 1392).

\section{Referensi}

Agetia, A., Hendra, G., L, L. H., \& Hariyanti. (2020). Penerapan Sistem Pendukung Keputusan Penliaian Kinerja Pegawai Menggunakan Metode Simple Additive Weighting (SAW) Pada Universitas XYZ. Jurnal IImu Komputer Indonesia (JIK), 5(1), 6-12.

Dian, C. O. (2019). Analisis Perbandingan Kualitas Pelayanan, Harga dan Kepuasan Konsumen Pengguna Layanan Go-Jek dan Grab (Studi Kasus pada Konsumen Pengguna .... http://repository.iainpurwokerto.ac.id/620 $0 /$

Hendini, A. (2016). Pemodelan Uml Sistem Informasi Monitoring Penjualan Dan Stok Barang (Studi Kasus: Distro Zhezha Pontianak). Jurnal Khatulistiwa Informatika, 2(9), 107-116. https://doi.org/10.1017/CBO9781107415 324.004

Indonesia, K. K. dan I. R. (2014). Kemkominfo: Penggunaan Internet di Indonesia Capai 82 Juta. Berita Kementrian Komunikasi Dan Informatika Republik Indonesia.

Indonesia, K. K. R. (2015). Indonesia Raksasa Teknologi Digital Di Asia. Sorotan Media Kementerian Komunikasi Dan Informatika Republik Indonesia.

Manahan, O. (2016). Perancangan Dan Pembuatan Sistem Pendukung Keputusan Penentuan Karyawan Terbaik Dengan Metode Saw Pada PT ISS Indonesia Cabang Medan. Jurnal Matik Penusa, 19(1), 44-52.

Natalia, K. V. (2018). Analisis Perbandingan Persepsi Kualitas Pelayanan, Harga Dan Kepuasan Konsumen Go-Jek Dan Grab. https://repository.usd.ac.id/30428/
Ningrum, T. W., Valentina, S., \& Dafid. (2016). Analisis dan Perancangan Sistem Pendukung Keputusan Pemberian Bonus Tahunan Karyawan dengan Metode SAW pada PT. XYZ. Jatisi, 3(1), 73-84.

Putra, D. W. T., \& Andriani, R. (2019). Unified Modelling Language (UML) dalam Perancangan Sistem Informasi Permohonan Pembayaran Restitusi SPPD. Jurnal Teknolf, 7(1), 32. https://doi.org/10.21063/jtif.2019.v7.1.3239

Rinaldhi, G. E. (2011). Penerapan Metode Simple Additive Weighting (SAW) Untuk Sistem Pendukung Keputusan Penentuan Penerimaan Beasiswa Bantuan Siswa Miskin (BSM) Pada SMA Negeri 1 Subah Kab. Batang. Jurusan Teknik Informatika Fakultas IImu Komputer Universitas Dian Nuswantoro Semarang, 1-9.

Saipurrohman. (1392). PENGARUH KUALITAS LAYANAN DAN PEMANFAATAN TEKNOLOGI TERHADAP KEPUASAN DAN LOYALITAS PELANGGANAN GOJEK DAN GRAB DALAM PERSPEKTIF EKONOMI ISLAM (Studi Pada Mahasiswa FEBI Jurusan Manajemen Bisnis Syariah UIN Raden Intaan

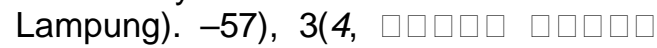
71.

http://marefateadyan.nashriyat.ir/node/15 0

Suendri. (2018). Implementasi Diagram UML (Unified Modelling Language) Pada Perancangan Sistem Informasi Remunerasi Dosen Dengan Database Oracle (Studi Kasus: UIN Sumatera Utara Medan). Jurnal IImu Komputer Dan Informatika, 3(1), 1-9.

Taslim, W. S. (2020). Analisis preferensi konsumen terhadap jasa angkutan online di pontianak (studi kasus: gojek vs grab). 3(1), 13-18.

Thoybah, Akhmad Suharto, P. W. (n.d.). Perbandingan Kualitas Pelayanan, Harga Dan Kepuasan Konsumen Gojek Dan Grab Pada Mahasiswa Fakultas Ekonomi Universitas Muhammadiyah Jember. 